\title{
Effects of Solid Lubricants on hard turning
}

\author{
GuoChen DU ${ }^{1, a}$, Ying CHEN ${ }^{1, b}$, ZhiZhen Wei ${ }^{1, c}$
}

${ }^{1}$ School of Mechanical and Electrical Engineering, Wei Fang University, Wei Fang 261061, China

awfuduguochen@163.com, bchenying711@163.com, ${ }^{\mathrm{c}} 1270145028 @ q q . c o m$

Keywords: Hard turning. Effective rake angle. Nose radius. Solid lubricants.

\begin{abstract}
Product quality is one of the most important criteria for the assessment of hard turning process. However, in view of the high temperatures developed in hard turning process, the surface quality deteriorates due to the tool wear. Because of the strict environmental restrictions on the use of cutting fluids, new cutting techniques are required to be investigated to reduce the tool wear. In the present work, the use of solid lubricants during hard turning has been explored while machining bearing steel with mixed ceramic inserts at different cutting conditions and tool geometry. Results show considerable improvement in the surface finish with the use of solid lubricants. Due to the presence of solid lubricants, there is a decrease of surface roughness values from 8 to $15 \%$ as compared to dry hard turning.
\end{abstract}

\section{Introduction}

Hardened steels are widely used in automobile, bearing, tool and die industries [1]. Nowadays, hard turning is being employed in industries as a substitute for grinding process. This has become possible due to the development of new cutting tool materials such as CBN and mixed ceramics [2].

Some researchers have reported the use of solid lubricants in the machining process. Shaji and Radhakrishnan [3] have investigated the effect of solid lubricant (graphite) on the surface grinding process. Results show the improvement of surface finish in case of harder materials with the application of solid lubricant. Gopal and Rao [4] have investigated the use of the solid lubricant in the grinding of the $\mathrm{SiC}$ has been investigated. It has been established by these authors that the surface finish improves with the graphite assisted machining. Reddy and Rao [5] have reported the performance of the end milling process by the use of the solid lubricants graphite and $\mathrm{MoS}_{2}$. Recently, Jianxin et al.[6] have reported the tribological behaviors of hot-pressed $\mathrm{Al}_{2} \mathrm{O}_{3} / \mathrm{TiC}$ ceramic composites with the additions of $\mathrm{CaF}_{2}$ solid lubricants.

The above-mentioned studies indicate that the surface finish can be improved by reducing the tool wear. The use of the solid lubricants in machining may be the viable alternative of cutting fluids as has been reported in some of the above mentioned studies. So an attempt has been made in this work to investigate the effect of tool geometry and the cutting conditions on the surface finish by using solid lubricants graphite and molybdenum disulphide in the hard turning of the bearing steel with the mixed ceramic tools and the comparison has been made between dry hard turning and the solid lubricants assisted hard turning.

\section{Experimentation}

According to the design of experiments, a central composite design was selected for experimentation to reduce the number of experiments. The cutting forces and surface finish were selected as the response variables. The cutting speed, feed, effective rake angle, and the nose radius are the independent variables in this study. The various process variables and their levels are shown in the Table 1 as under. a total of 31 experiments were carried out. All the experiments were carried out at a constant depth of cut of $0.2 \mathrm{~mm}$. A high precision MJ460 lathe was used for experimentation. It has high degree of accuracy and rigidity, which are required for the hard turning process.In this investigation, the workpiece material was the AISI 52100 steel of diameter $70 \mathrm{~mm}$. The workpiece material was heat treated (through-hardened) to get $58 \pm 02 \mathrm{HRC}$. The chemical composition of the 
material is shown in the Table 3. Mixed ceramic inserts of different geometry were used. ISO designation of ceramic inserts is SNGN with different nose radii and chamfer angles. ISO fesignation of the tool holder is CSBNR 2525M12. The approach angle of this tool holder was $75^{\circ}$. The surface roughness was measured with a Talysurf- 6 at $0.8 \mathrm{~mm}$ cut-off value. An average of three measurements was used as a response value. The tool wear was checked with a Mitutoyo opticalmicroscope $(1 \mu \mathrm{m}$ resolution) at 30×magnification to measure the wear after experimentation. For each experimental set, new cutting inserts have been used.

Table 1 Process variables and their levels

\begin{tabular}{c|c|c|c|c|c}
\hline Factors & Level-1 & Level-2 & Level-3 & Level-4 & Level-5 \\
\hline $\mathrm{v}(\mathrm{m} / \mathrm{min})$ & 50 & 75 & 100 & 125 & 150 \\
\hline $\mathrm{f}(\mathrm{mm} / \mathrm{r})$ & 0.04 & 0.08 & 0.12 & 0.16 & 0.20 \\
\hline$\alpha\left(^{\circ}\right)$ & 16 & 21 & 26 & 31 & 36 \\
\hline $\mathrm{r}(\mathrm{mm})$ & 0.4 & 0.8 & 1.2 & 1.6 & 2.0 \\
\hline
\end{tabular}

Table 2 Chemical composition of bearing steel

\begin{tabular}{c|c|c|c|c|c}
\hline $\mathrm{C} \%$ & $\mathrm{Mn} \%$ & $\mathrm{Si} \%$ & $\mathrm{Cr} \%$ & $\mathrm{~S} \%(\max )$ & $\mathrm{P} \%(\max )$ \\
\hline $0.98-1.1$ & $0.25-0.45$ & $\begin{array}{c}0.15-0.3 \\
5\end{array}$ & $\begin{array}{c}1.3-1 . \\
6\end{array}$ & 0.025 & 0.025 \\
\hline
\end{tabular}

The solid lubricants selected for this study were graphite and molybdenum disulphide. The fine powder of $2 \mu \mathrm{m}$ average particle size has been used. The apparatus has been so designed that it can supply the solid lubricant from $0.5 \mathrm{gm} / \mathrm{min}$ to $15 \mathrm{gm} / \mathrm{min}$. Figure 1 shows the variation of cutting force with flow rate at a cutting speed of $100 \mathrm{~m} / \mathrm{min}$, feed of $0.12 \mathrm{~mm} / \mathrm{rev}, 26^{\circ}$ effective rake angle and $1.2 \mathrm{~mm}$ nose radius in graphite and molybdenum disulphide assisted machining, respectively. It has been observed from graphite assisted machining that the cutting force decrease as the flow rate increases from $1 \mathrm{gm} / \mathrm{min}$ to $2 \mathrm{gm} / \mathrm{min}$. After that there is no substantial reduction of the cutting force even if the flow rate has been increased from $2 \mathrm{gm} / \mathrm{min}$ to $10 \mathrm{gm} / \mathrm{min}$. The similar trend has been observed for the other cutting conditions. The same is the case for molybdenum disulphide assisted machining also. It can be concluded that flow rate of $2 \mathrm{gm} / \mathrm{min}$ is sufficient to provide the required lubrication. Hence, in the present investigation, flow rate of graphite and molybdenum disulphide powders has been kept at $2 \mathrm{gm} / \mathrm{min}$ during the machining of hardened bearing steel (Fig. 1).

\section{Results and discussion}

The variation of surface roughness with respect to cutting speed for dry hard turning and solid lubricants assisted hard turning is shown in the Figs. 2 and 3. It can be observed from these figures that surface roughness was found to be decreasing with the increase of the cutting speed upto $125 \mathrm{~m} / \mathrm{min}$ and after that it again started increasing at high cutting speeds. This could be due to the reduction in the cutting forces at high speeds. The high value of surface roughness above $125 \mathrm{~m} / \mathrm{min}$ could be due to the wear of the cutting tools associated at higher speeds. Solid lubricant assisted hard turning produced low values of surface roughness compared to the dry hard turning. Among the two variants of the solid lubricant assisted machining, molybdenum disulphide assisted hard turning shows better results as compared to graphite assisted hard turning.

The variation of surface roughness with respect to the feed is shown in the Fig.4. Surface roughness is approximately constant upto $0.08 \mathrm{~mm} / \mathrm{r}$ and after this, it starts increasing with the increase of the feed. This is due the fact that more material has to removed per revolution, for which more energy is required, which ultimately increases the cutting forces and temperatures leading to high wear of the cutting tool, which might have resulted in the increase of surface roughness. However, surface roughness produced by the solid lubricants is again lower than that of dry hard turning process.

The trend of variation of the surface roughness with respect to the effective rake angle can also be observed from the Fig.5. It first decreases and then again increases. This could be due to the fact that 
the increase in effective negative rake angle reduces the tool wear and hence surface finish improves. Further increase in the effective rake angle increases the cutting forces making the machining process difficult and hence the deterioration in surface quality has been observed in the experimental values. Again surface roughness decreases with the application of the solid lubricants as can be seen from the figure.

The variation of the surface roughness with respect to the nose radius can be seen from the Fig.6. Surface roughness decreases with the increase of the nose radius. However, a slight increase in surface roughness can be observed beyond a nose radius of $1.8 \mathrm{~mm}$, which is due to the combined effect of the other process parameters in addition to the nose radius. Hence the judicious selection of nose radii in combination with suitable effective rake angle and cutting conditions should be used to produce the better surface quality. The effect of the solid lubricants can also be observed from this figure, which clearly indicates the solid lubricants are very much effective in producing the good quality hard turned parts.

From the above-mentioned results, it can be inferred that surface quality is better controlled by the solid lubricants in addition to the cutting conditions and the tool geometry parameters of the hard turning process. The net percentage decrease in the surface roughness value is also dependent upon the type of solid lubricant. So, there is a decrease of surface roughness values 8 to $10 \%$ due to graphite and 13 to $15 \%$ due to molybdenum disulphide. The decrease in the surface roughness due to solid lubricants can be attributed due the inherent lubricating properties of the solid lubricants even at extreme temperatures. This is due to the layered lattice structure of these lubricants. The lubricating action of the solid lubricants reduces the frictional forces between the chip and the tool interface and tool and the workpiece, hence reducing the temperatures developed and ultimately preventing the tool wear and prolonging the tool life, which result in surface quality improvement. The lower values of surface roughness produced by the molybdenum disulphide can be attributed to its strong adhesion as compared to the graphite.

\section{Conclusions}

The use of solid lubricants has been successful in reducing surface roughness during hard turning of bearing steel with mixed ceramic tools. Experimental results showed the superiority of the molybdenum disulphide hard turning over the graphite assisted hard turning. So, this methodology of using the solid lubricants appears to offer considerable benefits in terms of surface finish and environmental pollution point of view over the dry hard turning and hard turning with cutting fluids. This work also emphasizes that the proper selection of the solid lubricants along with cutting conditions and tool geometry is essential for achieving the overall improvement in hard turning process. The solid lubricant assisted hard turning may become a viable alternative to the dry and wet hard turning process.

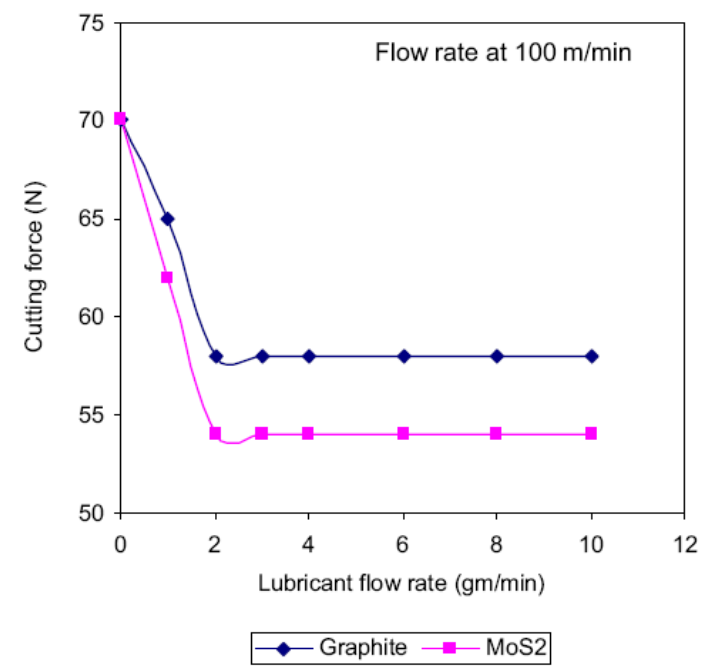

Fig. 1 Variation of cutting force with solid lubricants flow rate

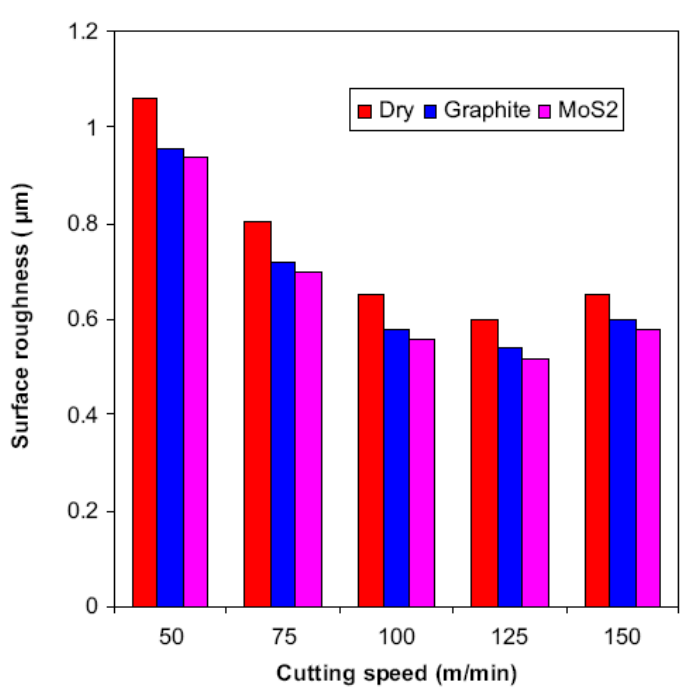

Fig. 2 Bar graph showing surface quality improvement 


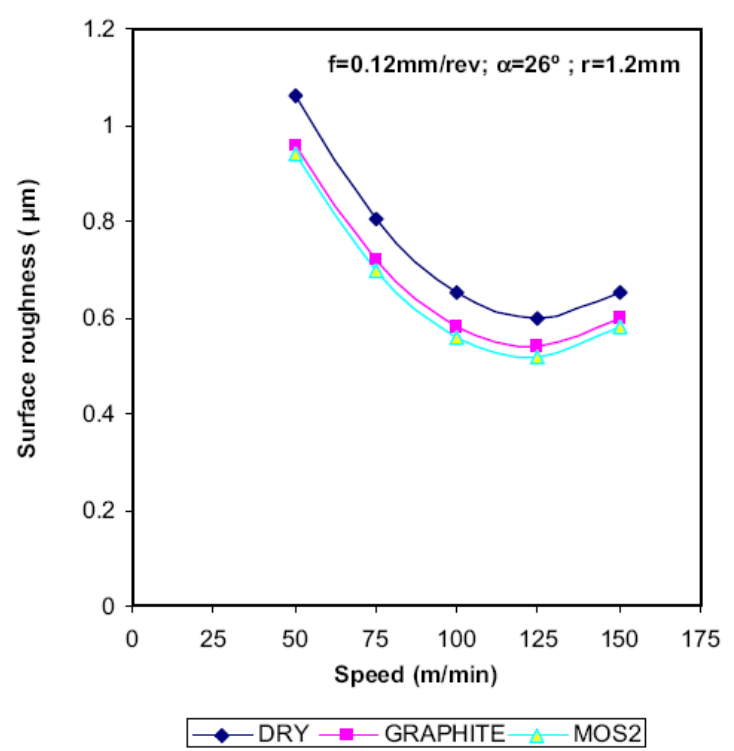

Fig. 3 Surface roughness variation with speed

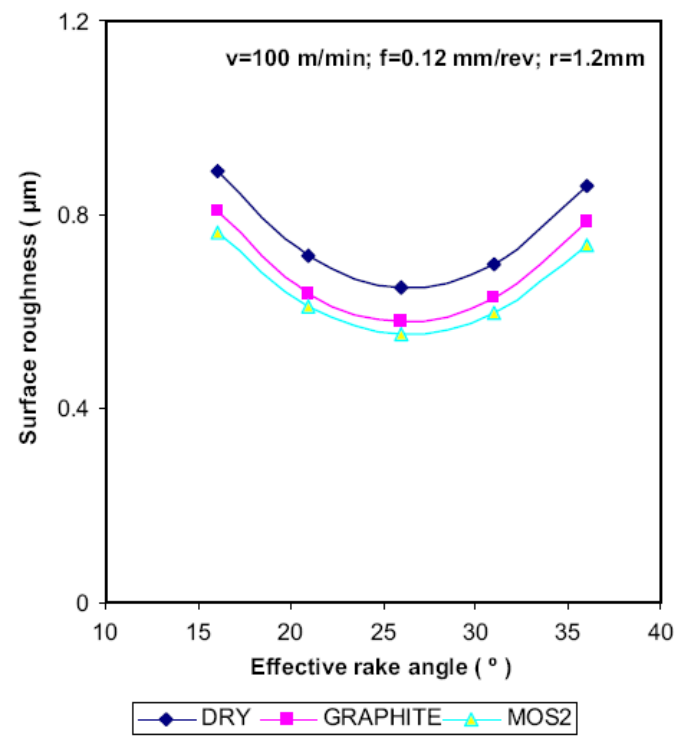

Fig. 5 Surface roughness variation with rake angle

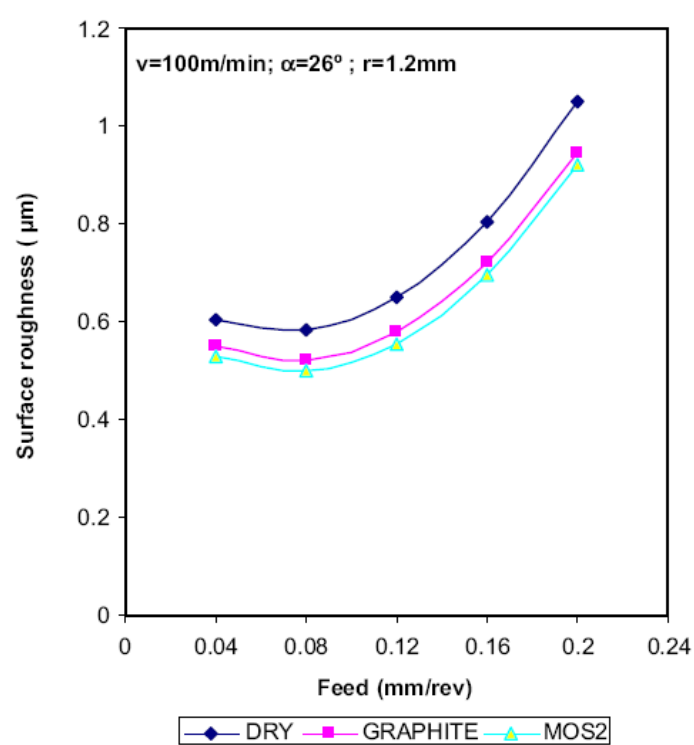

Fig. 4 Surface roughness variation with feed

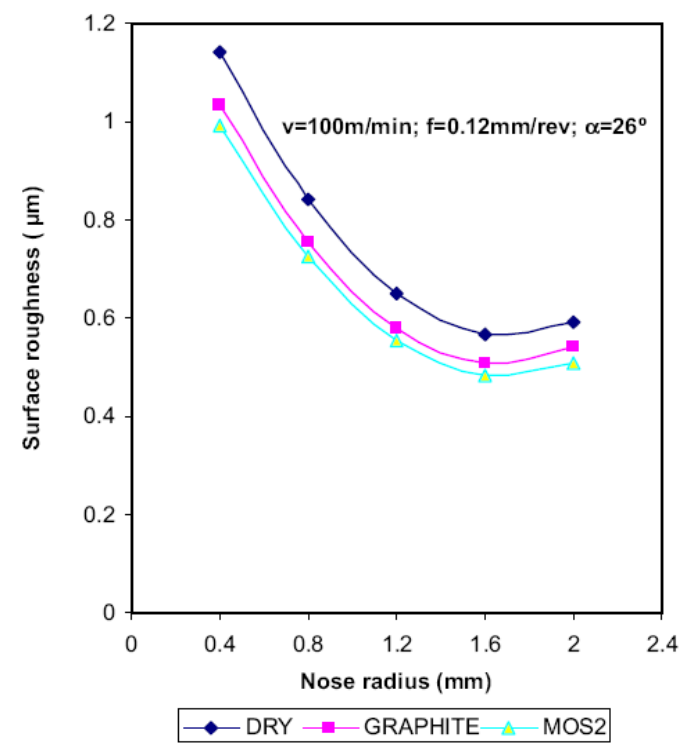

Fig. 6 Surface roughness variation with nose radius

\section{References}

[1] Shaji S, Radhakrishnan V (2002) Investigations on the application of solid lubricants in grinding. Proc Inst Mech Eng B J Eng Manuf 216(10):1325-1343

[2] König W, Komanduri R, Tönshoff HK, Ackershott G (1984) Machining of hard materials. Ann CIRP 33(2):417-427

[3] Shaji S, Radhakrishnan V (2002) An investigation on surface grinding using graphite as lubricant. Int J Mach Tools Manuf 42 (6):733-740

[4] VenuGopal A, Rao PV (2004) Performance improvement of grinding of SiC using graphite as a solid lubricant. Mater Manuf Process 19(2):177-186

[5] Reddy SKN, Rao PV (2005) Performance improvement of end milling using graphite as a solid lubricant. Mater Manuf Process 20(2):1-14

[6] Jianxin D, Tongkun C, Zeliang D, Jianhua L, Junlong S, Jinlong Z (2006) Tribological behaviors of hot-pressed A12O3/TiC ceramic composites with the additions of CaF2 solid lubricants. J Eur Ceram Soc 26(8):1317-1323 